\title{
ANALYSIS OF CORRELATIONS BETWEEN GROSS AND FINE MOTOR SKILLS, PHYSICAL FITNESS, AND THE LEVEL OF FUNCTIONING IN SCHOOLCHILDREN WITH INTELLECTUAL DISABILITIES
}

\author{
WALDEMAR SKOWROŃSKIIA, WITOLD WINNICKI², GRZEGORZ BEDNARCZUKIA, \\ IZABELA RUTKOWSKA ${ }^{1 A}$, WITOLD REKOWSKI'B
}

\author{
lJózef Pitsudski University of Physical Education in Warsaw, Faculty of Rehabilitation, Department of

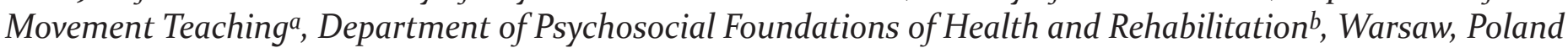 \\ 2Special Education School Complex No. 85 in Warsaw, Poland
}

Mailing address: Waldemar Skowroński, Józef Piłsudski University of Physical Education in Warsaw, Faculty of Rehabilitation, 34 Marymoncka Street, 00-968 Warsaw, tel.: +48 228354798 int. 620, 549, fax: +48 22 8651080, e-mail: waldemarskowronski@poczta.fm

\begin{abstract}
Introduction. Physical fitness affects motor and intellectual development. Having a wide range of motor skills makes it possible to learn about the surrounding world and expand one's knowledge. In the case of persons with intellectual disabilities, mastering gross and fine motor skills is the core of their development and functioning in society. The aim of the study was to analyse the relationship between physical fitness, gross and fine motor skills, and the level of functioning in schoolchildren with intellectual disabilities. Material and methods. The study involved 62 subjects whose age ranged from 9 to 24 years. Due to the large size and homogeneity of the group, the results of 26 subjects were considered in the analysis: 12 girls and 14 boys with moderate intellectual disability. Physical disability as well as gross and fine motor skills were measured with the BOT-2, TGMD2, and Eurofit Special tests. The level of functioning in society was assessed with a specially designed ICF-based questionnaire. Results. The study showed that girls had better motor skills than boys; this was reflected in the participants' level of functioning as girls displayed a higher level of functioning. Boys, despite better physical fitness, were ranked on a lower level of functioning. Conclusions. A relationship was found between gross and fine motor skills and the level of functioning, assessed with BOT-2 and TGMD-2. No relationship was found between physical fitness, assessed with Eurofit Special, and the level of functioning. Instead of using assessment tools for general fitness, one should measure specific motor skills when assessing physical and motor development in children with intellectual disabilities.
\end{abstract}

Key words: intellectual disability, physical fitness, gross and fine motor skills, level of functioning

\section{Introduction}

Individuals with intellectual disabilities constitute $1 \%$ of the whole population, while in the case of school-age children, this figure is approximately $2-3 \%[1,2,3]$. The largest group consists of individuals with mild disabilities $(85 \%)$, followed by those with moderate $(10 \%)$, severe (3-4\%), and profound (1-2\%) disabilities [2].

Movement is an indispensable part of human existence, and physical activity occurs already in the first days of life. The importance of movement is noticeable when it allows us to occupy particular social roles, do professional work and sports activity, and undergo physiotherapeutic treatment [4]. Movement and speech enable us to interact with the surrounding environment and help us develop in biological and social terms [5].

With motor development, children acquire more and more complex skills [6]. Proper motor skills development is a source of fun, satisfaction, and joy for them. Being capable of performing specific motor tasks allows them to take part in games and activities together with their peers, thus improving their social competences. The lack of appropriate mental and physical stimulation may result in failure to make use of the developmental potential and, consequently, may lead to secondary develop- mental disorders, including intellectual development disturbances.

When disabled people are described, the focus is usually on their potential and abilities rather than shortcomings and limitations. A typical change that has occurred in recent years is the fact that disabled persons are perceived as fully capable individuals who can fend for themselves thanks to overcoming barriers and making use of facilities.

The International Classification of Functioning, Disability and Health (ICF) is an example of a positive perception of disability. The name of the classification itself points to an essential change [7, 8]; the document is a description and classification of the functioning of human beings regardless of their disability level and health status [9].

The aim of the study was to determine correlations between gross and fine motor skills, physical fitness, and the level of functioning (evaluated with the use of a specially designed battery of questions based on ICF) in a group of girls and boys with moderate intellectual disabilities.

The study also sought to define correlations between age, body height, body mass, and the level of functioning in the girls and the boys under investigation. 


\section{Material and methods}

The research was carried out in Special Education School Complex No. 85 in Warsaw at the turn of 2015 and 2016.

The research material included data obtained from students whose parents or legal guardians signed the study participation consent form. One hundred and thirty-two parents or legal guardians were asked to give their consent, 62 of whom did. Therefore, 62 students with moderate and severe intellectual disabilities took part in the study. The exclusion criteria included severe intellectual disability and moderate intellectual disability with multiple disabilities, autism spectrum disorders, or Down syndrome.

The study was approved by the Research Ethics Committee of the Józef Piłsudski University of Physical Education in Warsaw. Moreover, parental consent and children's assent were obtained prior to commencing the research.

The analysis included results obtained from 26 students (12 females and 14 males) with moderate intellectual disabilities. On average, the girls were a year older than the boys, but the difference was not significant. Table 1 illustrates the age characteristics of the students examined.

Table 1. Age characteristics of the study participants [years]

\begin{tabular}{|c|c|c|c|c|}
\hline Age & $\overline{\boldsymbol{x}}$ & SD & Min & Max \\
\hline Girls & 18.9 & 3.9 & 12.3 & 23.2 \\
\hline Boys & 17.9 & 3.5 & 12.0 & 23.2 \\
\hline
\end{tabular}

$\bar{x}=$ mean $\mathrm{SD}=$ standard deviation; $\mathrm{Min}=$ minimum; $\mathrm{Max}=$ maximum.

Table 2 shows the data regarding the body height and mass of the study participants. Basic data concerning body build show differences in mean body height: the boys were significantly taller than their female counterparts by an average of $10.4 \mathrm{~cm}$. The differences observed in mean body mass were unusual since the girls were $9.9 \mathrm{~kg}$ heavier than the boys, though the difference was not significant.

Table 2. Body height $[\mathrm{cm}]$ and body mass $[\mathrm{kg}]$ of the study participants

\begin{tabular}{|c|c|c|c|c|c|}
\hline Parameter & Sex & $\overline{\boldsymbol{x}}$ & SD & Min & Max \\
\hline \multirow{2}{*}{$\begin{array}{c}\text { Body height } \\
(\mathrm{cm})\end{array}$} & Girls & $156.1^{*}$ & 7.7 & 144.0 & 169.5 \\
\cline { 2 - 6 } & Boys & $166.5^{*}$ & 13.4 & 135.5 & 182.0 \\
\hline $\begin{array}{c}\text { Body mass } \\
(\mathrm{kg})\end{array}$ & Girls & 64.8 & 15.0 & 39.0 & 93.0 \\
\cline { 2 - 6 } & Boys & 54.9 & 13.4 & 29.0 & 79.0 \\
\hline
\end{tabular}

$\bar{x}=$ mean $; \mathrm{SD}=$ standard deviation $; \mathrm{Min}=$ minimum $; \mathrm{Max}=$ maximum .

* = statistically significant difference at 0.05 .

BOT-2 was used as a diagnostic tool, as it is applied in measuring the motor skills of individuals aged 4-21 years. Wuang and $\mathrm{Su}[10]$ proved it is a reliable tool for assessing the motor proficiency of persons with intellectual disabilities. Also, van der Linde et al. [11] pointed to BOT-2 as a clinical tool used in diagnostics, screening, and evaluation in this group of people.

A shortened version of the test (BOT-2 SF) was applied in the study. This version is recommended for quick screening in schools (including schools for intellectually disabled children). It consists of 14 tasks selected from the full version of the test [12]. They are grouped into 8 areas: fine motor precision, fine motor integration (concerning fine motor control), manual dexterity (hand coordination), bilateral coordination (body coordination), balance (balance reactions, running speed, and agility), and upper-limb coordination and strength (strength and agility) [13].

The second test which was applied to collect data is called TGMD-2. It is one of the most commonly used diagnostic tools for assessing the motor development of children aged 3-10 years [14]. However, researchers also use it to evaluate the motor skills of children with intellectual disabilities [15]. TGMD-2 is composed of two parts that measure gross motor skills, that is locomotor and object control skills. Each of the parts consists of six tests that are presented in Table 3.

Table 3. TGMD-2 - locomotor and object control tests

\begin{tabular}{|l|l|}
\hline \multicolumn{1}{|c|}{ Locomotor } & \multicolumn{1}{c|}{ Object control } \\
\hline 1. Run & 1. Striking a stationary ball \\
2. Gallop & 2. Stationary dribble \\
3. Hop & 3. Catch \\
4. Leap & 4. Kick \\
5. Horizontal jump & 5. Overhead throw \\
6. Slide & 6. Underhand roll \\
\hline
\end{tabular}

Based on Ulrich 2000.

Each test includes between 3 and 5 criteria marked from 0 to 1 point depending on whether participants met the performance criteria. Each test is performed twice, and the maximum score ranges from 6 to 10 (depending on the number of criteria to be met in a given test) [16]. The scores from particular tests are totalled to obtain a raw score (a maximum of 96 pts). After performing the tests from both parts, the raw score is converted to a standard score. Then, standard scores from both parts are combined and converted to a gross motor quotient, which is compared to the norms [15].

The third tool used in the study is known as the Eurofit Special test, which is a battery of tests designed to assess physical fitness in individuals with intellectual disabilities. It includes a point scale ( $\mathrm{T}$ scale) which determines the level of the motor abilities of a subject compared to the population with regard to age, sex, and the level of intellectual disability. The tests included in the Eurofit Special test do not require complex motor skills, and the performance procedures are easy to comprehend [17]. The test consists of six tasks: a balance walk on a bench (general balance), a 25-m run (running speed and agility), a sit-and-reach test performed by the bench (flexibility), a standing long jump (explosive power), a 2-kg medicine ball push (strength and upper-limb coordination), and 30-s sit-ups (trunk strength - abdominal muscle endurance). Independent research has confirmed the reliability and validity of the Eurofit Special test [18].

The ICF-based questions regarding areas of functioning were the last research tool used in the study. This tool was prepared by Witold Rekowski and Waldemar Skowroński at the Faculty of Rehabilitation of the University of Physical Education in Warsaw. It assessed the effects of motor skills development on the functioning of children in their environment. The original ICF made it possible to modify score scales. In order to assess functional levels of the study participants based on the ICF (CY version), a diagnostic questionnaire covering five areas of functioning was developed. Due to the fact that the questionnaire was to be completed by parents untrained in using the ICF, instead of using the original ICF qualifiers, the parents performed assessments on 10-point Likert scales. This modification was to increase the effectiveness of the assessments. The ICF was used in a similar manner when evaluating the effects of rehabilitation programmes for individuals with physical disabilities and for 
4-16-year-old children with spina bifida who used wheelchairs provided by the Foundation for Active Rehabilitation [19, 20, 21]. The questionnaire used in the present study consisted of questions regarding functions or activities performed by a child and marked with ICF codes. A scale from 1 to 10 pts was used, where 1 referred to a large limitation of the function or activity, while 10 meant there were no problems. The questions were grouped into 5 categories:

1) mobility ( 5 questions - a maximum of 50 pts);

2) performing simple and complex tasks and manipulating objects ( 4 questions - up to 40 pts);

3) self-care (1l questions - up to 110 pts);

4) cognitive and emotional competences (3 questions - up to 30 pts);

5) social competences (10 questions - up to 100 pts).

When particular test batteries were applied, instructions provided in practical manuals that accompanied the tools were followed [22, 23, 24]. The ICF-based questionnaire form regarding areas of functioning was completed by the parents (or legal guardians) of the students who participated in the study.

\section{Results}

The analysis of BOT- 2 results revealed that there was a significant difference in favour of the girls compared to the boys. The girls displayed higher levels of gross and fine motor skills (49.6 pts) than their male peers (35.5 pts). Table 4 shows the BOT-2 results.

Table 4. BOT-2 results [pts]

\begin{tabular}{|c|c|c|c|c|}
\hline Sex & $\overline{\boldsymbol{x}}$ & SD & Min & Max \\
\hline Girls & $49.6^{*}$ & 17.7 & 15.0 & 71.0 \\
\hline Boys & $35.5^{*}$ & 22.5 & 3.0 & 66.0 \\
\hline
\end{tabular}

$\bar{x}=$ mean SD = standard deviation; Min = minimum; Max = maximum.

* = statistically significant difference at 0.05 .

The data obtained using TGMD-2 revealed a significant difference regarding locomotor tests, but not regarding object control tests. Compared to the boys, the girls were more skilful when it came to locomotor tests (33.9 pts) as well as object control tests $(26.0 \mathrm{pts})$. The boys scored 21.8 pts and 21.3 pts, respectively. Table 5 illustrates the TGMD- 2 results.

Table 5. TGMD-2 results [pts]

\begin{tabular}{|c|c|c|c|c|c|}
\hline TGMD-2 & Sex & $\overline{\boldsymbol{x}}$ & SD & Min & Max \\
\hline \multirow{2}{*}{ Locomotor } & Girls & $33.9^{*}$ & 6.4 & 24.0 & 46.0 \\
\cline { 2 - 6 } & Boys & $21.8^{*}$ & 14.1 & 4.0 & 45.0 \\
\hline \multirow{2}{*}{$\begin{array}{c}\text { Object } \\
\text { control }\end{array}$} & Girls & 26.0 & 10.6 & 7.0 & 40.0 \\
\cline { 2 - 6 } & Boys & 21.3 & 13.5 & 5.0 & 43.0 \\
\hline
\end{tabular}

$\bar{x}=$ mean SD = standard deviation; Min = minimum; Max = maximum.

* $=$ statistically significant difference at 0.05 .

While analysing the Eurofit Special test results (Table 6), it could be noted that the mean physical fitness scores of the boys (129.0 pts) were higher than those of the girls (99.2 pts). However, the difference was not significant.
Table 6. Eurofit Special results [pts]

\begin{tabular}{|c|c|c|c|c|}
\hline Sex & $\overline{\boldsymbol{x}}$ & SD & Min & Max \\
\hline Girls & 99.2 & 52.2 & 31.0 & 203.0 \\
\hline Boys & 129.0 & 106.1 & 9.0 & 312.0 \\
\hline
\end{tabular}

$\bar{x}=$ mean $; \mathrm{SD}=$ standard deviation $; \mathrm{Min}=$ minimum $; \mathrm{Max}=$ maximum.

The results obtained with the use of the ICF-based questions regarding areas of functioning showed that there were no significant differences. The girls outperformed their male counterparts in all aspects of social functioning (Table 7).

Table 7. ICF-based question results regarding areas of functioning [pts]

\begin{tabular}{|l|c|c|c|c|c|}
\hline \multicolumn{1}{|c|}{ Areas of functioning } & Sex & $\overline{\boldsymbol{x}}$ & SD & Min & Max \\
\hline \multirow{2}{*}{ 1. Mobility } & Girls & 39.2 & 8.9 & 19.0 & 50.0 \\
\cline { 2 - 6 } & Boys & 31.5 & 14.3 & 10.0 & 47.0 \\
\hline \multirow{2}{*}{$\begin{array}{l}\text { 2. Performing simple } \\
\text { and complex tasks, and } \\
\text { manipulating objects }\end{array}$} & Girls & 33.8 & 7.1 & 22.0 & 40.0 \\
\cline { 2 - 6 } & Boys & 27.0 & 9.9 & 11.0 & 39.0 \\
\hline \multirow{2}{*}{$\begin{array}{l}\text { 3. Self-care } \\
\text { 4. Cognitive and emotional }\end{array}$} & Girls & 92.3 & 15.4 & 69.0 & 110.0 \\
\cline { 2 - 6 } & Boys & 73.1 & 25.9 & 32.0 & 110.0 \\
\cline { 2 - 6 } competences & Boys & 20.2 & 6.7 & 9.0 & 28.0 \\
\hline \multirow{2}{*}{ 5. Social competences } & Girls & 78.6 & 13.9 & 60.0 & 96.0 \\
\cline { 2 - 6 } & Boys & 78.2 & 18.6 & 35.0 & 98.0 \\
\hline
\end{tabular}

$\bar{x}=$ mean $; \mathrm{SD}=$ standard deviation $; \mathrm{Min}=$ minimum $; \mathrm{Max}=$ maximum.

Table 8 illustrates correlations between the age, body height, and body mass of the girls examined and ICF-based questions regarding areas of functioning as well as the BOT-2, TGMD-2, and Eurofit Special tests.

The girls' age correlated strongly with the first four areas and all areas together. No correlation was found between their age and the fifth area.

The body height of the girls correlated strongly with the first three areas. No correlations were noted between their body height and the remaining two areas or all areas together.

Strong correlations were observed between the girls' body mass and areas 2 and 3 as well as all areas together. No correlations with areas 1,4 , or 5 were revealed.

The girls' age correlated strongly with the BOT- 2 results. No correlations were found between age and the TGMD-2 or Eurofit Special tests. Body height and mass did not correlate with the BOT-2, TGMD-2, or Eurofit Special tests. 
Table 8. Correlations of age, body height, and body mass with ICFbased questions regarding areas of functioning and the BOT-2, TGMD2, and Eurofit Special tests in the girls

\begin{tabular}{|c|c|c|c|c|c|c|c|c|c|c|}
\hline 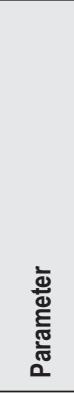 & 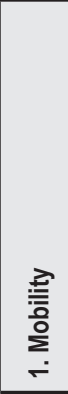 & 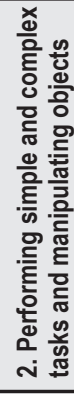 & 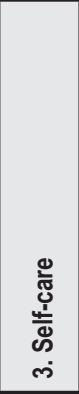 & 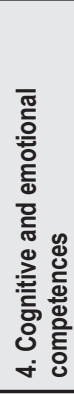 & 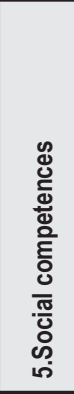 & 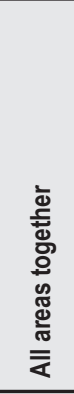 & 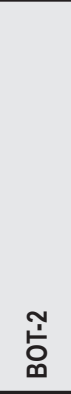 & 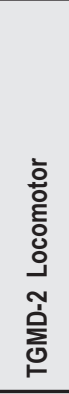 & 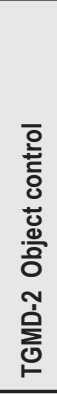 & 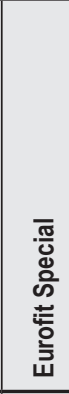 \\
\hline Age & $.656^{*}$ & $.826^{* *}$ & $.800^{* *}$ & $.722^{* *}$ & .417 & $.808^{* *}$ & $.614^{*}$ & .353 & .525 & .299 \\
\hline $\begin{array}{l}\text { Body } \\
\text { height }\end{array}$ & $.702^{*}$ & $.601^{*}$ & $.636^{*}$ & .399 & -.021 & .552 & .405 & -.059 & .564 & -.088 \\
\hline $\begin{array}{l}\text { Body } \\
\text { mass }\end{array}$ & .372 & $.627^{*}$ & $.621^{*}$ & .376 & .404 & $.595^{\star}$ & .031 & .358 & .347 & -.060 \\
\hline
\end{tabular}

* = correlation significant at 0.05 .

** $=$ correlation significant at 0.01 .

Table 9 shows the correlations of the age, body height, and body mass of the boys with ICF and the BOT-2, TGMD-2, and Eurofit Special tests. The analysis of the boys' age, body height, and body mass with regard to ICF revealed no correlations between those variables and particular areas of ICF or the complete ICF.

Strong correlations were noted between the boys' age and BOT-2 as well as object control in TGMD-2. No correlations were observed between age and the TGMD-2 locomotor or Eurofit Special tests.

The body height of the boys correlated strongly with BOT2 and object control in TGMD-2. However, it did not correlate with the TGMD-2 locomotor or Eurofit Special tests.

The boys' body mass did not correlate with any of the tests.

Table 9. Correlations of age, body height, and body mass with ICFbased questions regarding areas of functioning and the BOT-2, TGMD2 and Eurofit Special tests in the boys

\begin{tabular}{|c|c|c|c|c|c|c|c|c|c|c|}
\hline 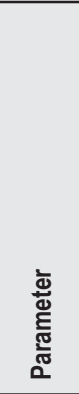 & 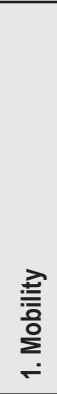 & 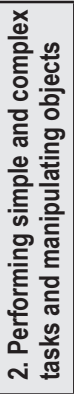 & 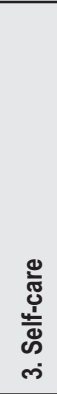 & 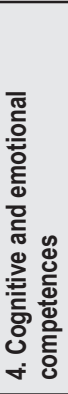 & 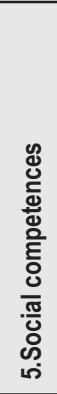 & 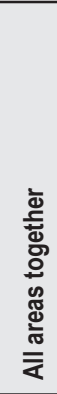 & 官 & 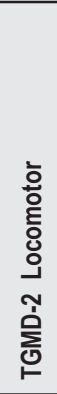 & 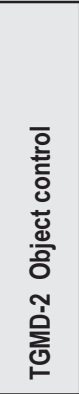 & 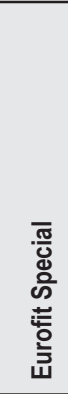 \\
\hline Age & .381 & .174 & .501 & .185 & .127 & .378 & $.733^{* *}$ & .451 & $.667^{* *}$ & -.506 \\
\hline $\begin{array}{l}\text { Body } \\
\text { height }\end{array}$ & .234 & .259 & .431 & .482 & .104 & .354 & $.798^{* *}$ & .331 & $.632^{*}$ & -.527 \\
\hline $\begin{array}{l}\text { Body } \\
\text { mass }\end{array}$ & .431 & .219 & .315 & .267 & 150 & .335 & .422 & .210 & .331 & -.449 \\
\hline
\end{tabular}

* = correlation significant at 0.05 .

** $=$ correlation significant at 0.01 .
Table 10 presents correlations of ICF-based questions regarding areas of functioning with the BOT-2, TGMD-2, as well as Eurofit Special tests in the girls. Strong correlations were observed between areas 1 and 2 and object control in TGMD-2 as well as BOT-2. There was a strong correlation between area 3 and object control in TGMD-2. Area 4 correlated significantly with BOT-2 and object control in TGMD-2. No correlations were noted between area 5 and the tests. All areas together correlated with BOT-2 and object control in TGMD-2.

Table 10. Correlations of ICF-based questions regarding areas of functioning with the BOT-2, TGMD-2, and Eurofit Special tests in the girls

\begin{tabular}{|l|c|c|c|c|}
\hline \multicolumn{1}{|c|}{ Areas of functioning } & BOT-2 & $\begin{array}{c}\text { TGMD-2 } \\
\text { Locomotor }\end{array}$ & $\begin{array}{c}\text { TGMD-2 } \\
\text { Object } \\
\text { control }\end{array}$ & $\begin{array}{c}\text { Eurofit } \\
\text { Special }\end{array}$ \\
\hline 1. Mobility & $.694^{*}$ & .329 & $.811^{* *}$ & .011 \\
\hline $\begin{array}{l}\text { 2. Performing simple } \\
\text { and complex tasks and } \\
\text { manipulating objects }\end{array}$ & $.609^{*}$ & .391 & $.644^{*}$ & .419 \\
\hline 3. Self-care & .436 & .215 & $.595^{*}$ & .245 \\
\hline $\begin{array}{l}\text { 4. Cognitive and emotional } \\
\text { competences }\end{array}$ & $.802^{* *}$ & .400 & $.683^{*}$ & .268 \\
\hline 5. Social competences & .115 & .470 & .494 & .116 \\
\hline All areas together & $.629^{*}$ & .481 & $.744^{* *}$ & .255 \\
\hline
\end{tabular}

** $=$ correlation significant at 0.01 .

* $=$ correlation significant at 0.05 .

Table 11 illustrates correlations between ICF-based questions regarding areas of functioning and the BOT-2, TGMD-2, as well as Eurofit Special tests in the boys. Significant correlations were found between area 2 of ICF and the BOT-2 and Eurofit Special tests. There were significant correlations between area 3 and TGMD-2 (locomotor and object control tests) as well as BOT-2. Significant correlations were also observed between the complete ICF and the TGMD-2 object control and Eurofit Special tests. No significant correlations were found in the case of the other elements.

Table 11. Correlations of ICF-based questions regarding areas of functioning with the BOT-2, TGMD-2, and Eurofit Special tests in the boys

\begin{tabular}{|l|c|c|c|c|}
\hline \multicolumn{1}{|c|}{ Areas of functioning } & BOT-2 & $\begin{array}{c}\text { TGMD-2 } \\
\text { Locomotor }\end{array}$ & $\begin{array}{c}\text { TGMD-2 } \\
\text { Object } \\
\text { control }\end{array}$ & $\begin{array}{c}\text { Eurofit } \\
\text { Special }\end{array}$ \\
\hline 1. Mobility & .152 & .169 & .287 & -.394 \\
\hline $\begin{array}{l}\text { 2. Performing simple } \\
\text { and complex tasks and } \\
\text { manipulating objects }\end{array}$ & $.609^{*}$ & .301 & .343 & $-.630^{*}$ \\
\hline 3. Self-care & $.601^{*}$ & $.702^{* *}$ & $.819^{* *}$ & -.448 \\
\hline $\begin{array}{l}\text { 4. Cognitive and emotional } \\
\text { competences }\end{array}$ & .396 & .292 & .310 & $-.576^{*}$ \\
\hline 5. Social competences & .228 & .269 & .378 & -.319 \\
\hline All areas together & .402 & .450 & $.556^{*}$ & $-.568^{*}$ \\
\hline
\end{tabular}

** $=$ correlation significant at 0.01 .

* = correlation significant at 0.05 . 


\section{Discussion}

Individuals with intellectual disabilities are a group of people for whom everyday life is a challenge. They need to cope with their own weaknesses and also a lack of understanding or even disrespect. Visual and auditory impairments as well as balance and sensory integration dysfunctions that accompany the disability often result in greater problems associated with everyday activities and social relations. Concentration, memory, and visual-motor coordination disturbances limit the possibility of doing various leisure time activities.

The study enabled us to determine gross and fine motor skills, physical fitness levels, and functioning levels assessed with the ICF-based questions regarding areas of functioning in individuals with moderate intellectual disabilities. As for body height, BOT-2, and the TGMD-2 locomotor sub-test, there were significant differences between the girls and the boys. However, no significant differences were observed in the case of age, body mass, object control in TGMD-2, Eurofit Special, or areas of functioning.

The highest number of correlations with areas of functioning was noted in the case of object control in TGMD-2 in the girls. These correlations were revealed in 4 out of 5 areas of functioning. Correlations between gross and fine motor skills examined with the BOT-2 test were found in 3 out of 5 areas. No significant correlations between the girls' physical fitness examined with the use of Eurofit Special tests and areas of functioning were observed. As far as the boys are concerned, a correlation was found between gross motor skills examined using TGMD-2 (locomotor and object control tests) and 1 out of 5 areas only. A correlation was noted between the boys' gross and fine motor skills examined with BOT- 2 also in 1 out of 5 areas. No correlation was revealed between their physical fitness levels and areas of functioning.

There were correlations between gross and fine motor skills assessed with BOT-2 as well as gross motor skills evaluated using TGMD-2 and areas of functioning in the girls or in the boys.

The authors could not find any studies that would focus on individuals with intellectual disabilities in the presented ICFbased questions regarding areas of functioning. The most similar research was carried out by Marchewka [25], who examined 95 students aged 15-22 with moderate and severe intellectual disabilities. She determined correlation coefficients between physical fitness and the results of Gunzburg's test of social competences. In all the analysed elements of the Eurofit Special tests, physical fitness determined the level of the social competences of the youth examined. The higher the level of the subjects' physical fitness was, the better their social competences were.

Jaworska [26] examined 9 children with intellectual disabilities. She compared the motor development of each child with their social maturity. Those who exhibited higher physical fitness levels were also more socially adjusted.

The current research did not reveal correlations between physical fitness and the level of social competences assessed with the ICF-based questions regarding areas of functioning in the girls or in the boys.

Another research problem that the authors addressed was the analysis of correlations between the age, body height, and body mass of the girls and the boys under investigation and the level of functioning evaluated with the use of the ICF-based questions regarding areas of functioning.

There was a correlation between the girls' age and 4 out of 5 areas, while their body height correlated with 3 out of 5 areas.
Furthermore, their body mass correlated with 2 out of 5 areas. In the group of the boys, no correlations were found between age, body height, or body mass and any of the areas of functioning.

An attempt was also made to analyse correlations between the age, body height, and body mass of the girls and the boys and their physical fitness levels as well as gross and fine motor skills.

The analysis revealed correlations between the girls' age and gross and fine motor skills in BOT-2. No correlations between their body mass and height and physical fitness or gross and fine motor skills were observed. In the case of the boys, correlations between their age and gross and fine motor skills were noted in BOT-2 as well as object control in TGMD-2. Correlations were also found between their body height and gross and fine motor skills in BOT-2 as well as object control in TGMD-2. No correlations between the boys' body mass and physical fitness or gross and fine motor skills were observed.

When examining 1,583 individuals with intellectual disabilities, Skowroński [18] revealed that correlations between physical fitness and morphological parameters usually displayed low values, even though there were statistically significant. Moreover, he observed that physical fitness indicated stronger morphological conditioning in the boys. This is partly in line with the findings of the present study.

The results of our research showed that the girls demonstrated higher levels of motor skills than their male peers, whereas the boys obtained higher scores in physical fitness tests. During the testing of specific motor skills that required precision, appropriate movement rhythm, and spatio-temporal orientation, the subjects experienced considerable difficulties in meeting the criteria of proper performance. This indicates that tools which evaluate not only physical fitness but also gross and fine motor skills should be used to assess the motor development of individuals with intellectual disabilities. Knowing that physical activity as well as motor activities performed by children also affect the development of their intellectual sphere, it is necessary to teach and improve various motor skills.

The analysis of the research results revealed that the girls displayed higher levels of functioning in all areas assessed with the ICF-based questions regarding areas of functioning. Despite demonstrating higher levels of physical fitness, the boys achieved lower levels of functioning according to the areas of functioning.

The limitation of the present study is that it was conducted on 26 individuals and that there was a considerable diversity of results.

The research ought to be replicated on a larger sample size in order to obtain more reliable results. It would also be worth determining the correlations between ICF-based areas of functioning and other tools used in various branches of knowledge, for example in pedagogy, special pedagogy, or psychology.

In France as well as in Belgium and Denmark, ICF is currently used by all members of rehabilitation teams and in social care, professional rehabilitation, and special education [9].

The findings of the present study regarding gross and fine motor skills and physical fitness may be used to examine the motor development of students and to evaluate objectives included in individual educational and therapeutic programmes.

The determination of motor development levels may also be useful in solving educational problems. Elliot et al. [27] and Berg et al. [28] investigated the effects of movement exercises on aggressive behaviour levels. They observed that strength training reduced the level of such behaviours and led to an increase 
in adaptation and motor skills. If one sets achievable goals involving new experiences which bring joy and boost self-reliance and self-confidence, it is possible to develop the necessary personality traits in individuals with intellectual disabilities.

The majority of people with more serious intellectual disabilities will never be able to read fluently, count in mind, earn their living, or do professional sport. Most of them will never be self-reliant. Visual and auditory impairments as well as visualmotor coordination and proprioceptive disorders are additional barriers which hinder their participation in important events and favourite activities and affect their social life. Gross and fine motor skills as well as physical fitness may enable intellectually disabled persons to make use of all their skills and abilities. If they can hold a crayon, they will draw their favourite animal. Being able to hold a paintbrush, they will take part in outdoor painting workshops. If they are capable of cutting out elements of a colouring book, they will make a greeting card for their next of kin (fine motor skills). Thanks to having the ability to walk, they will be able to move to a place that is protected from the wind. If they can run and kick a ball, they may be able to play an entire match during the Special Olympics. Thanks to being able to jump aside, they will avoid being splashed by a car driving through a puddle (gross motor skills). Being able-bodied, they will use the toilet on their own, drink water after opening the bottle, and make sandwiches. If they go to the seaside with their guardian, they will be able to jump waves and go for a walk along the beach.

If properly evaluated and developed, gross and fine motor skills facilitate the everyday functioning of intellectually disabled individuals to the largest extent, despite all the barriers and limitations.

The highest number of correlations was noted between areas of functioning and gross and fine motor skills which were assessed with the BOT- 2 and TGMD- 2 tests. The results obtained with the use of those tools showed significant differences in the group examined. It is noteworthy that both batteries of tests consist of detailed motor tasks that make it possible to assess particular types of skills. This may also be the reason why more correlations with areas of functioning (which provide a thorough description of one's functioning) were observed. The third tool, i.e. Eurofit Special, did not reveal correlations with areas of functioning, which may have stemmed from the fact that the motor tasks to be performed were less diverse. In the case of children with intellectual disabilities, being capable of performing a task is probably more important than motor-related accomplishments. Their skills are more crucial than the results achieved within a limited range of skills.

\section{Conclusions}

The following conclusions can be drawn from this study:

1. There were a number of correlations between gross and fine motor skills and the level of functioning of the girls and the boys. There were more correlations in the case of the girls. No correlations were found between physical fitness and the level of functioning in the girls or boys.

2. Correlations between the girls' body height and mass and the level of their functioning were revealed. No such correlations were noted in the boys.

3. There were correlations between age of the girls and the boys and their gross and fine motor skills. No correlations between their age and physical fitness were observed.
4. The girls manifested slightly higher levels of gross and fine motor skills, while the boys exhibited higher levels of physical fitness.

5. Compared to the boys, the girls demonstrated higher levels of functioning according to ICF-based areas of functioning.

\section{Literature}

1. Bobińska K. (2012). Physiotherapy in psychiatry. In A. Florkowski (ed.), Intellectual disability (pp. 90-95). Warszawa: Wydawnictwo Lekarskie PZWL. [in Polish]

2. Bobińska K., Pietras T., Gałecki P. (2012). Intellectual disability - etiopathogenesis, epidemiology, diagnosis, therapy. Wrocław: Wydawnictwo Continuo. [in Polish]

3. Zwierzchowska A. (ed.) (2015). Biomedical and pedagogical fundamentals of the development and evaluation of children with special educational needs. Katowice: AWF Katowice. [in Polish]

4. Szopa J., Mleczko E., Żak S. (1999). Fundamentals of anthropomotorics. Kraków: Wydawnictwo PWN. [in Polish]

5. Raczek J. (2010). Anthropomotorics. An outline of human motor theory. Warszawa: Wydawnictwo Lekarskie PZWL. [in Polish]

6. Borkowska M., Szwilig Z. (2012). NDT - Bobath method. Guidelines for parents. Warszawa: Wydawnictwo Lekarskie PZWL. [in Polish]

7. Morgulec-Adamowicz N., Kosmol A., Molik B. (2015). Adapted physical activity for physiotherapists. In N. MorgulecAdamowicz, A. Kosmol, B. Molik (eds), The ICF model of functioning and disability and adapted physical activity (pp. 41-47). Warszawa: Wydawnictwo Lekarskie PZWL. [in Polish]

8. Ronikier A. (2012). Functional diagnostics in physiotherapy. In A. Ronikier (ed.), ICF and how it functions in physiotherapy (pp. 159-162). Warszawa: Wydawnictwo Lekarskie PZWL. [in Polish]

9. Wilmowska-Pietruszyńska A., Bilski D. (2013). International Classification of Functioning, Disability and Health. Disability - issues, problems, solutions II(7), 5-20. [in Polish]

10. Wuang Y.-P., Su C.-Y. (2009). Reliability and responsiveness of the Bruininks-Oseretsky Test of Motor Proficiency - Second Edition in children with intellectual disability. Research in Developmental Disabilities 30, 847-855.

11. van der Linde B.W., van Netten J.J., Otten E., Postema K., Geuze R.H., Schoemaker M.M. (2015). A systematic review of instruments for assessment of capacity in activities of daily living in children with developmental co-ordination disorder. Child: Care, Health and Development 41, 23-34.

12. Fotini V., Antonis K., Nickos A., Ioannis F., Kyriakos T. (2009). Motor assessment of preschool aged children: A preliminary investigation of the validity of the BruininksOseretsky Test of Motor Proficiency - Short Form. Human Movement Science 28(4), 543-550.

13. Piek J., Hands B.P., Licari M. (2012). Assessment of motor functioning in the preschool period. Neuropsychology Review 22(4), 402-413.

14. Williams H., Monsma E.V. (2006). Psychoeducational assessment of preschool children (4th ed.). In B.A. Bracken, R.J. Nagle (eds), Assessment of gross motor development (pp. 397-433). Hillsdale, NJ: Lawrence Erlbaum Associates.

15. Rintala P., Loovis E.M. (2013). Measuring motor skills in Finnish children with intellectual disabilities. Perceptual $\mathcal{E}$ Motor Skills: Motor Skills E Ergonomics 116(1), 294-303. 
16. Franjko I., Žuvela F., Kuna D., Kezić A. (2013). Relations between some anthropometric characteristics and fundamental movement skills in eight-year-old children. Croatian Journal of Education 15, 195-209.

17. Wieczorek M., Urban S., Wilińska A. (2014). Motor fitness of Down syndrome boys with moderate intellectual disabilities (pilot study). Postępy Rehabilitacji 2, 49-56. [in Polish]

18. Skowroński W. (2003). Motor fitness and body build of individuals with mild, moderate, and severe intellectual disabilities aged 10.5-17.5 years. Warszawa: AWF Warszawa. [in Polish]

19. Jagodziński R., Pawlak K. (2011). The use of ICF in programmes aimed at the social and professional activation of persons with physical disabilities - presentation of project findings. Niepetnosprawność - Zagadnienia, Problemy, Rozwiązania 1, 26-62. [in Polish]

20. Jagodziński R. (2013). The use of ICF as a tool for diagnosing, planning and evaluating in a programme aimed at the social and professional activation of persons with physical disabilities. Niepetnosprawność - Zagadnienia, Problemy, Rozwiq̨zania 11, 67-103. [in Polish]

21. Rekowski W., Długołęcka A. (2014). Outcome assessment of a programme aimed at the complex social activation of 4-16-year-old children using wheelchairs performed with the International Classification of Functioning, Disability and Health. Niepełnosprawność i Rehabilitacja 1, 73-89. [in Polish]

22. Bruininks H.R., Bruininks D.B. (2005). Bruininks-Oseretsky Test of Motor Proficiency, Second Edition. Administration Easel. Minneapolis: NCS Pearson.

23. Ulrich A.D. (2000). Test of Gross Motor Development. Second Edition. Austin, Texas: Pro-Ed Publishers.

24. Skowroński W. (1999). Eurofit Special. Motor fitness test for individuals with intellectual disability. Warszawa: AWF Warszawa. [in Polish]

25. Marchewka A. (2005). Selected components of life activity and levels of intellectual disability. Kraków: AWF Kraków. [in Polish]

26. Jaworska E. (2001). Social maturity vs. motor development in selected autistic children. Wychowanie Fizyczne i Sport 45(4), 525. [in Polish]

27. Elliot R.O., Dobbin A.R., Rose G.D., Soper H.V. (1994). Vigorous, aerobic exercise versus general motor training activities: Effects on maladaptive and stereotypic behaviors of adults with both autism and mental retardation. Journal of Autism and Developmental Disorders 24(5), 565-576.

28. Berg W.K., Wacker D.P., Ebbers B., Wiggins B., Fowler M., Wilkes P. (1995). A demonstration of generalization of performance across settings, materials, and motor responses for students with profound mental retardation. Behavior Modification 19(1), 119-143.

Submitted: December 5, 2016

Accepted: November 28, 2017 